\title{
BMJ Open Factors affecting anaemia among women of reproductive age in Nepal: a multilevel and spatial analysis
}

\author{
Dev Ram Sunuwar (D) ,,2 Devendra Raj Singh (D) , ${ }^{1,2}$ Bipin Adhikari (D) , ${ }^{3}$ \\ Santosh Shrestha, ${ }^{4}$ Pranil Man Singh Pradhan (i) ${ }^{5,6}$
}

To cite: Sunuwar DR, Singh DR, Adhikari B, et al. Factors affecting anaemia among women of reproductive age in Nepal: a multilevel and spatial analysis. BMJ Open 2021;11:e041982. doi:10.1136/ bmjopen-2020-041982

- Prepublication history and additional materials for this paper is available online. To view these files, please visit the journal online (http://dx.doi. org/10.1136/bmjopen-2020041982).

Received 23 June 2020 Revised 24 January 2021 Accepted 16 March 2021

Check for updates

(c) Author(s) (or their employer(s)) 2021. Re-use permitted under CC BY-NC. No commercial re-use. See rights and permissions. Published by BMJ.

For numbered affiliations see end of article.

Correspondence to Dev Ram Sunuwar; devramsunuwar@gmail.com

\section{ABSTRACT}

Objective The main objective of this study was to explore the factors affecting anaemia among women of reproductive age (WRA) in Nepal using spatial and multilevel epidemiological analysis.

Design This cross-sectional study analysed data from the 2016 Nepal Demographic and Health Survey. Spatial analysis was performed using ArcGIS software V.10.8 to identify the hot and cold spots of anaemia among WRA (15-49 years). Data were analysed using multilevel mixedeffect logistic regression analysis.

Setting Nepal.

Participants A total of 6414 WRA were included in the analysis.

Main outcome measure Anaemia defined by WHO as haemoglobin level less than $120 \mathrm{~g} / \mathrm{L}$ in non-pregnant women and less than $110 \mathrm{~g} / \mathrm{L}$ in pregnant women.

Results The spatial analysis showed that statistically significant hotspots of anaemia were in the southern Terai region (four districts in province 1, eight districts in province 2, one district in Bagmati province, two districts in province 5 and one district in Sudurpaschim province) of Nepal. At the individual level, women who underwent female sterilisation (adjusted OR, a0R: 3.61, 95\% Cl 1.10 to 11.84 ), with no education (aOR: $1.99,95 \% \mathrm{Cl}: 1.17$ to 3.39 ), and from middle socioeconomic class families (a0R: $1.65,95 \% \mathrm{Cl}: 1.02$ to 2.68) were more likely to be anaemic, whereas, older women ( $\geq 35$ years) (a0R: 0.51 , $95 \% \mathrm{Cl}: 0.26$ to 0.97$)$ and those women who were using hormonal contraceptives (aOR: $0.63,95 \% \mathrm{Cl}: 0.43$ to 0.90 ) were less likely to be anaemic. At the community level, women from province 2 (aOR=2.97, 95\% Cl: 1.52 to 5.82 ) had higher odds of being anaemic.

Conclusion WRA had higher odds of developing anaemia, and it varied by the geographical regions. Nutrition-specific and nutrition-sensitive interventions can be tailored based on the factors identified in this study to curb the high burden of anaemia.

\section{INTRODUCTION}

Anaemia remains a significant public health problem in developing countries despite advances made in health sciences. ${ }^{1}$ Approximately one-third of the population is affected by anaemia globally. ${ }^{2}{ }^{3}$ South and Southeast Asian countries account for the largest burden of anaemia with estimated

\section{Strengths and limitations of this study}

This study uses comprehensive, and nationally representative data with haemoglobin level.

- The combined statistical methods including multilevel and spatial analysis were applied, which takes into account the role of geographical risk profile and determinants of anaemia among women of reproductive age in Nepal.

- Due to the cross-sectional design, it was difficult to determine the cause-and-effect relationships between the predictors and outcome variable (anaemia)

- Other potential confounding factors of anaemia such as nutrient intake, worm infestations, other nonmodifiable risk factors and other qualitative factors were beyond the scope of this study.

- This study could not distinguish the types of anaemia such as nutritional, genetic and infectious.

prevalence of $52.5 \%$ among women of reproductive age (WRA). ${ }^{4}$ The highest prevalence over the past 26 years was $55.2 \%$ in $1990 .^{5}$ Despite the implementation of a ' 1000 days nutrition programme' among various other programmes, targeted to a mother with newborn babies in South Asia, the reduction in anaemia among pregnant women has not been significant. ${ }^{6}$ To accelerate reduction of anaemia, the World Health Assembly has set a target of achieving a $50 \%$ reduction of anaemia among WRA by 2025 relative to $2010 .^{7}$ However, not a single South Asian country is on the way to achieve the 2025 targets. 8

The Government of Nepal has set targets in line with various global and national indicators such as Multi-Sectoral Nutrition Plan II (2018-2022), and Sustainable Development Goals 2030 for the reduction of anaemia. ${ }^{9} 10$ Despite the historical efforts in preventing anaemia through the implementation of national nutrition programmes and policies including iron-folic acid supplementation across the country, the prevalence of anaemia 
among WRA has been increasing steadily from $35 \%$ in 2011 to $41 \%$ in $2016 .{ }^{11} 12$ These figures suggest that anaemia continues to be a serious public health problem in Nepal. ${ }^{13}$

Anaemia in WRA is associated with multiple conditions and consequences such as preterm delivery, ${ }^{14}$ miscarriage,${ }^{15}$ low birth weight,${ }^{16}$ child growth faltering, impairment of cognitive function, increased susceptibility to infection and poverty. ${ }^{17}{ }^{18}$ It is also associated with increased risk of prenatal and maternal mortality. ${ }^{16} 19$ Approximately $20 \%$ of maternal deaths are caused by anaemia and it is also considered as an additional risk factor for $50 \%$ of all maternal deaths. ${ }^{20} 21$

Contributing factors and distribution of anaemia include a complex interplay of political, ecological, social and biological factors. ${ }^{22}$ In Nepal, anaemia among WRA is associated with various socioecological factors. In the southern Terai of Nepal, low community education status, gender based-inequality, poor health seeking behaviour, ${ }^{23-25}$ inadequate dietary intake during pregnancy, ${ }^{26-28}$ lack of diversified diet, ${ }^{12} 2729$ high burden of hookworm infection and malaria, ${ }^{30-32}$ and high amount of arsenic in potable water ${ }^{33}$ were identified as factors contributing to anaemia. High prevalence of anaemia in the mountainous region were attributed to among others, food insecurity and low dietary diversity, ${ }^{12} 2734$ poor health services, ${ }^{25}$ illiteracy and gender-based inequality. ${ }^{23} 24$

To decrease the burden of anaemia, it is necessary to generate adequate evidence in terms of the role and contribution of individual, household and the community level factors along with the geographical risk profile of anaemia. Only a few studies in the past have explored factors affecting anaemia among WRA using nationally representative Nepal Demographic and Health Survey (NDHS) data. ${ }^{35-37}$ So far, no studies have used spatial data to explore the geographical hotspots (high prevalence) of anaemia among WRA using cluster sampling of the NDHS data. In addition, population in Nepal has diverse characteristics in terms of their culture, ethnicity and geographical locations. Within the latitude of $193 \mathrm{~km}$ (North to South), Nepal bears tropical/subtropical landscape on the south, and temperate to alpine in the North, with an elevation ranging from $70 \mathrm{~m}$ to the summit of Mount Everest $(8848 \mathrm{~m}) .{ }^{38}$ The distinct characteristics such as dietary habit, lifestyle and socioeconomic status linked to the geographical regions of Nepal are unique and pose risk of developing anaemia. Exploring spatial patterns and factors affecting anaemia by geographical region is therefore critical to inform the plans and policies for targeted anaemia control and prevention programmes. ${ }^{39}$ The main objective of this study was to explore the spatial distribution and contributing factors of anaemia among WRA in Nepal.

\section{METHODS}

\section{Patient and public involvement}

This study used a publicly available data set (NDHS). There were no patients involved.

\section{Data source}

This study was based on the data from NDHS 2016, a nationally representative cross-sectional survey. This survey was carried out as part of the DHS programme by New ERA (a private non-profit research organisation based in Kathmandu) under the guidance of the Ministry of Health, Government of Nepal and was supported by ICF international and US Agency for International Development. The study population for this study was WRA from the NDHS 2016.

\section{Study settings and sampling strategy}

The sample for the 2016 NDHS was designed to provide estimates of population health, and nutrition indicators including fertility and mortality rates for the overall country, provinces, development regions, urban and rural municipalities, and for the ecological zones: Terai, Hills, and Mountains. The NDHS 2016 used a stratified, twostage cluster sampling design. The survey used enumeration areas (EAs) which is a primary sampling unit and was selected from 383 wards in both rural $(n=199)$ and urban $(n=184)$ areas with probability proportional to size method. In the second stage, 30 households on average within EAs were selected using a systematic sampling technique. A more detailed methodology of the NDHS has been published elsewhere. ${ }^{12}$ All WRA (pregnant and non-pregnant) with complete sociodemographic and nutritional characteristics who were residents or who had slept in the selected households on the night before the survey were eligible for the survey. The details of the sample size selection in the NDHS 2016 are presented in figure 1 .

\section{Study variables}

\section{Outcome variables}

Haemoglobin level was measured using capillary blood by a battery-operated portable HemoCue rapid testing machine and was adjusted for altitude and smoking status. ${ }^{12}$ According to the WHO, for non-pregnant and pregnant women aged 15-49 years, any form of anaemia is defined as haemoglobin concentration $<120 \mathrm{~g} / \mathrm{L}$ and $<110 \mathrm{~g} / \mathrm{L}$, respectively. ${ }^{40}$ The categories of anaemia were further dichotomised into 'anaemic' and 'not anaemic'.

\section{Predictor's variables}

Predictors of anaemia were selected based on the literature review. ${ }^{435-3739}$ The wide range of sociodemographic, individual, household and community factors were hypothesised to increase the likelihood of anaemia. The predictors of anaemia including both individual-level and community-level factors were included in the analysis. The coding strategy of individual-level and communitylevel factors are presented in online supplemental table 1.

\section{Individual-level factors}

A total of 11 individual-level factors were identified, and that included, for example, respondent's age, education level, occupation, wealth index, nutritional status, 


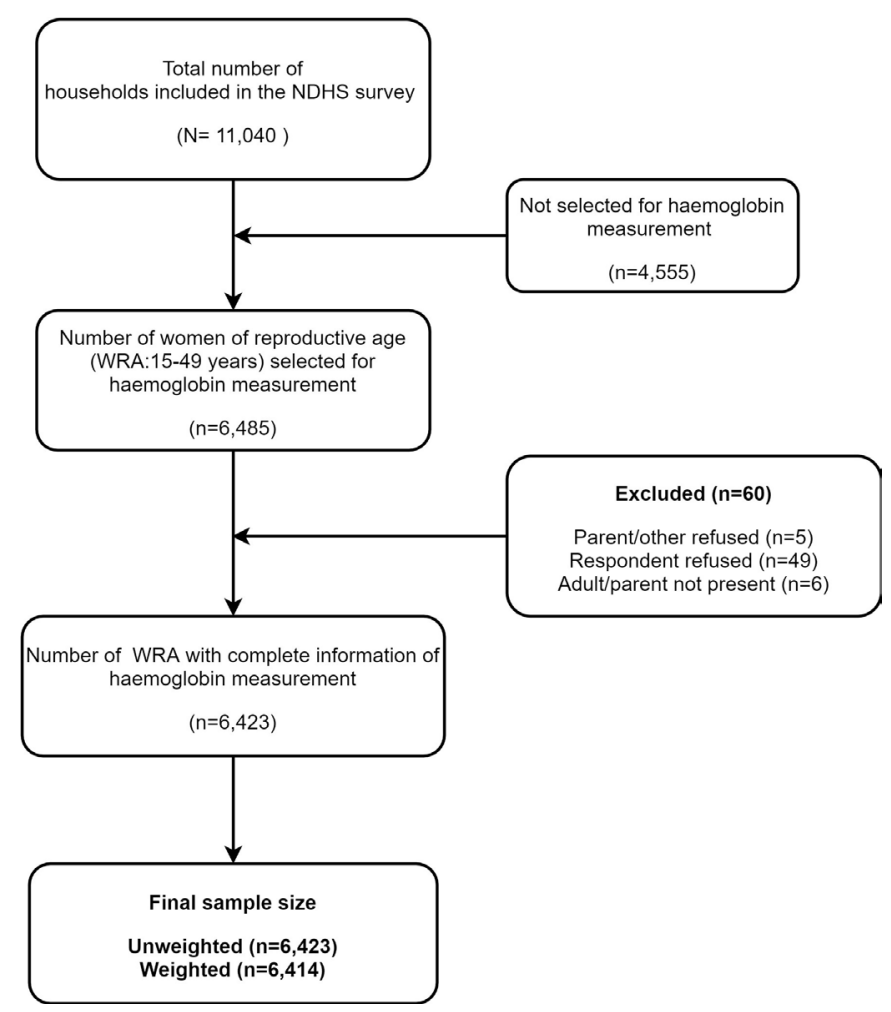

Figure 1 Flow chart for sample size selection. NDHS, Nepal Demographic and Health Survey; WRA, women of reproductive age.

pregnancy status and minimum dietary diversity for WRA (MDD-W). The MDD-W was calculated using the guideline of the modified Food and Nutrition Technical Assistance III (FANTA) project tool developed by the Food and Agriculture Organization of the United Nations. ${ }^{41}$

\section{Community-level factors}

The six different factors were included in the communitylevel factors that included place of residence, province, community wealth, community female education, community safe water access and community toilet facility. The selection of community-level factors were based on the group of women living in similar settings. ${ }^{39}$ If more women have shared features such as place of residence, province, type of water source and toilet facility; it was considered to have the same effect on anaemia among WRA. ${ }^{39}$ For community level wealth and female education, we constructed the aggregate continuous community-level predictor variables by aggregating individual-level characteristics at the community (cluster) level. We dichotomised the aggregate variables into 'high' or 'low' based on the distribution of the proportion values calculated for each community, ${ }^{42}$ but it was not applicable for the provinces and place of residence. Based on distribution of the aggregate variable (normal or non-normal), mean and median was used as a cut-off point for the categorisation of community-level variables, respectively. The community wealth was categorised as 'high' if the proportion of women from richest (rich, richest) households in the community was above $21 \%$ and 'low' if the proportion was $0 \%-21 \%$. Community female education was defined as the mean percentage of women in the community with at least primary education and above. ${ }^{43}$ Water supply and sanitation guidelines based on the WHO and UNICEF Joint Monitoring Progamme were used to define improved toilet facility and improved water source. ${ }^{44}$

\section{Data analysis}

Statistical analysis

Data were analysed using Stata/MP V.14.1 (StataCorp). The 'svy' command was used to account for sampling weights, clustering, and stratification in complex survey data. Weighted frequencies, weighted percentage, mean and SD were used for the descriptive analysis. Pearson $\chi^{2}$ test for categorical variables and independent t-test for continuous variables were used. The multilevel mixedeffect logistic regression analysis was performed to estimate the adjusted OR (aOR) and to estimate the extent of random variations between communities.

Four models were created and were fitted. Model 1 (empty model) was fitted without predictor variable to test random variability in the intercept and to estimate the intraclass correlation (ICG). ${ }^{45}$ Model 2 examined the effects of individual-level characteristics, model 3 examined the effects of community-level variables, and model 4 examined the effects of both individual and community-level characteristics simultaneously. In the multilevel mixed-effect logistic regression models, the fixed effects estimated the association between the likelihood of anaemia among WRA and the individual-level and community-level factors, and the findings are reported in terms of aOR, and $95 \%$ CIs. To prevent statistical bias in the multilevel logistic regression model, we examined and reported multicollinearity among the predictor variables using variation inflation factors (VIF). In this study, we used ' 10 ' as a cut-off value for the maximum level of VIF. ${ }^{46}$ The random effects are expressed as ICC, ${ }^{45}$ and proportional change in variance (PCV). ${ }^{47}$ The ICG was calculated to evaluate the cluster variability; and PCV can measure the total variation due to factors at the individual and community levels. ${ }^{45}$ Models fit were assessed using Akaike information criterion and the Bayesian information criterion. Considering the nested structure of the survey data, a multilevel model is considered to be appropriate than ordinary single-level regression model because it provides correct parameter estimates by handling the cluster data. ${ }^{48} 49$

\section{Spatial analysis}

Spatial analysis was performed using ArcGIS software V.10.8, and base files of the administrative provinces and districts of Nepal were obtained from Government of Nepal, Ministry of Land Management, ${ }^{50}$ and Natural Earth. ${ }^{51}$ The global positioning system (GPS) data set for NDHS was obtained from the DHS website after receiving the approval letter. The prevalence of anaemia and standardised prevalence ratio (SPR) were computed for both the districts and provinces in Stata/MP V.14.1 
software and were later transferred to Excel spreadsheet. These data were imported into the ArcGIS software to link the reported anaemia prevalence for each cluster to the corresponding geographical location (survey cluster data). The spatial variations of the prevalence of anaemia among WRA by both districts and provinces were visualised. To estimate the SPR (ratio of observed prevalence to expected prevalence $)^{52}$ of anaemia among WRA, we first determined the prevalence of anaemia for both districts and provinces. District and province wise prevalence rate of anaemia among WRA was multiplied by the national prevalence rate of $41 \%$ (normalised to the national prevalence of $41 \%$ ).

The Local Moran's I, Gettis-Ord G-statistics tool in ArcGIS software was used to compute to measure how spatial autocorrelation of anaemia among WRA varies across different locations in Nepal. The Getis-Ord G-statistics identifies statistically significant spatial clusters of hotspot clusters (high-high) and cold spot clusters (lowlow) ${ }^{53}{ }^{54}$ Hotspot analysis computes Z-score and $p$ value to determine the statistical significance of the clustering of anaemia over the study area at different significance levels simultaneously. ${ }^{545}$ The statistical significance of autocorrelation was determined by $\mathrm{z}$-scores and $\mathrm{p} \leq 0.05$ with a $95 \%$ CIs. ${ }^{39} 55$ An anaemia hotspot was defined as the occurrence of high prevalence rates of anaemia clustered together on the map. Anaemia cold spot was referred to the occurrence of low prevalence rates of anaemia clustered together on the map. ${ }^{39} 55$ The spatial pattern and distribution of anaemia prevalence rates among WRA in Nepal are visualised on the map (figure 2).

\section{Ethical consideration}

The details on ethical procedures used in this survey have been published elsewhere. ${ }^{12}$ We registered and requested for access to both main data and GPS data from the DHS website $^{56}$ and received an approval to access and download the DHS data file. DHS programme collected data following a written informed consent from each individual. All individual identifiers were precluded from the final dataset in this study.

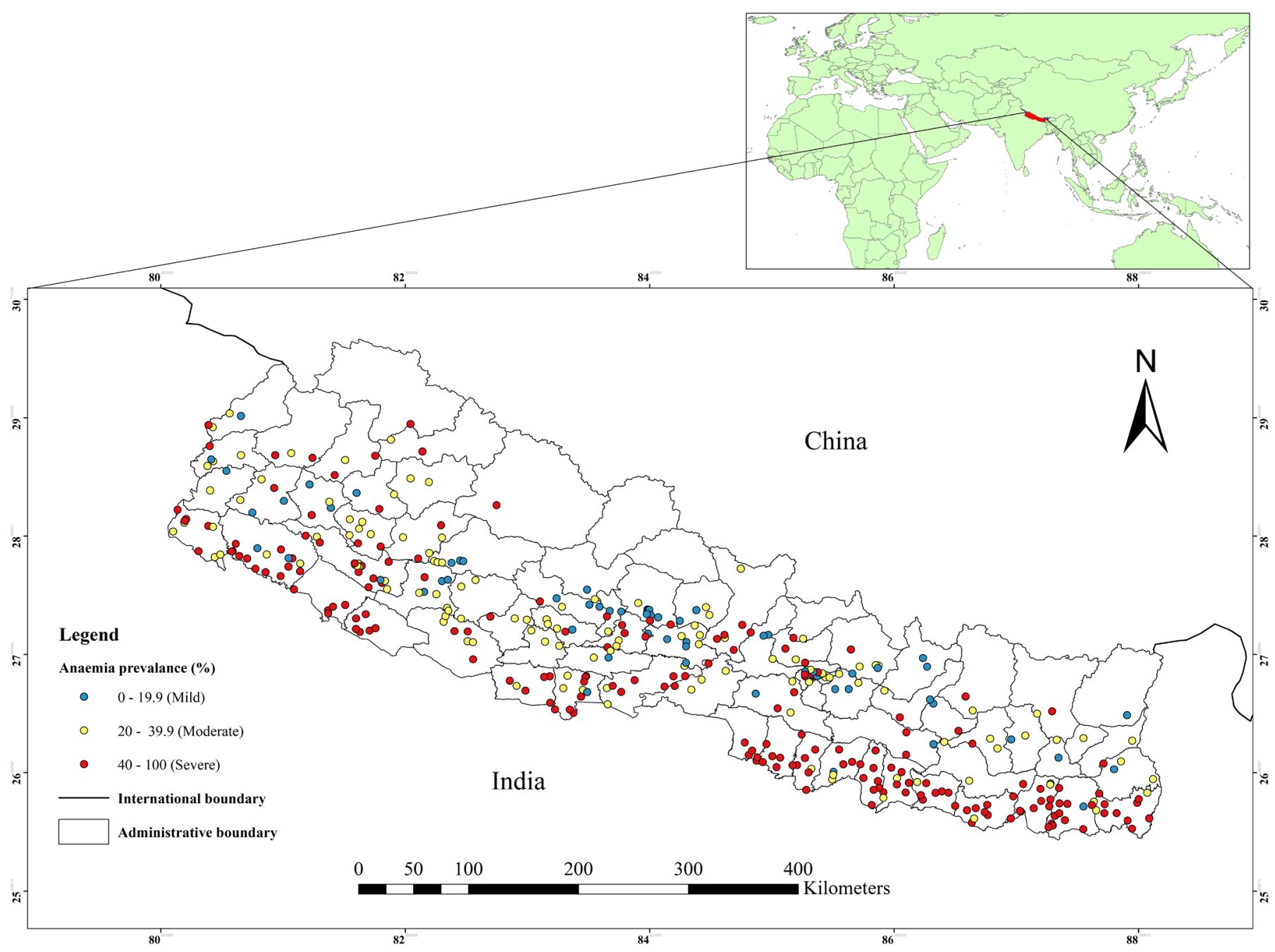

Figure 2 Study area map and observed anaemia prevalence among women of reproductive age for the NDHS survey clusters. NDHS, Nepal Demographic and Health Survey. 


\section{RESULTS}

\section{Sociodemographic characteristics of study participants}

In this study, a total of 6414 WRA were included in the analysis (table 1$)$. The mean $( \pm \mathrm{SD})$ age of the study participants was $29( \pm 9.7)$ years. More than one-third $(38.1 \%)$ of the participants were from age group 15-24 years, and $35.5 \%$ of women had attended secondary level education. Nearly one-quarter $(22.4 \%)$ of study participants were from richer wealth quintiles and more than half $(59.7 \%)$ of the women were not using any contraceptive methods, and a half $(50.6 \%)$ of the participants consumed more than five food types. More than three-quarters $(77.1 \%)$ of participants had mosquitoe bed nets for sleeping. High proportion of women $(68.8 \%)$ belonged to urban areas, and were from Bagmati province $(21.9 \%)$. More than half $(54.2 \%)$ of the women had the highest percentage of community female education, while, nearly two-thirds $(64 \%)$ of the women belonged to a low percentage of community female wealth index. Majority of the participants had improved sources of drinking water $(91 \%)$ and type of toilet facility $(84.1 \%)$ (table 1$)$.

\section{Prevalence of anaemia among WRA}

In the current study, the overall prevalence of any anaemia across Nepal was $41 \%$ (95\% CI: $38.5 \%$ to $42.9 \%)$. At the individual level, the prevalence of anaemia was higher among younger age group $(43.6 \%)$, and women who attended at least secondary level education $(42.7 \%)$. The higher prevalence of anaemia were found in middle socio-economic class families $(48.9 \%)$. The prevalence of anaemia was more among women who had undergone female sterilisation (53.7\%), and those who consumed less than five food groups $(51 \%)$. At the community level, the prevalence of anaemia was higher in women who came from province $2(57.7 \%)$. The high prevalence of anaemia was found in community with low female education $(47.9 \%)$, female wealth index $(44.3 \%)$ and who did not have improved toilet facility $(51.5 \%)$ (table 1).

\section{Factors affecting anaemia among WRA}

The fixed effects (a measure of association) and the random-effects for the risk of developing anaemia among WRA are presented in table 2. The results of the empty model (model 1) showed that there was statistically significant variability in the odds of anaemia between communities $(\tau=0.627, \mathrm{p}<0.001)$. The ICC in the empty model implied that $16 \%$ of the total variance for the risk of developing anaemia was attributed to differences between the communities. In individual-level factors (model 2), women who did not have formal education $(\mathrm{aOR}=2.22,95 \%$ CI: 1.35 to 3.82) compared with those with higher education, and who belonged to middle-class families $(\mathrm{aOR}=1.38,95 \%$ CI: 0.86 to 2.20$)$ compared with the family from poorest families were found to have higher odds of anaemia. Older women had $52 \%$ lower (aOR=0.48, 95\% CI: 0.24 to 0.83 ) odds of developing anaemia compared with younger women. Women who used hormonal contraceptive methods had $35 \%$ lower $(\mathrm{aOR}=0.65,95 \%$ CI: 0.46 to 0.92$)$ odds of anaemia compared to who did not use contraceptive methods. The ICC in model 2 indicated that $11.8 \%$ of the variation in WRA anaemia was attributable to differences across communities. The PCV indicated that $29.3 \%$ of the variance in WRA anaemia across communities was explained by the individual-level characteristics.

The community level (model 3) showed that women from province 2 had 2.5 times higher $(\mathrm{aOR}=2.51$, 95\% CI: 1.79 to 3.53 ) odds of anaemia compared to women from Bagmati province. Women who belonged to communities with a low percentage of the wealthy households had 1.48 times higher $(\mathrm{aOR}=1.48$, 95\% CI: 1.21 to 1.80 ) odds of anaemia compared to those coming from high percentage of the wealthy household; and women residing in communities with a low percentage of community female education had 1.39 times higher $(\mathrm{aOR}=1.39,95 \%$ CI: 1.15 to 1.68$)$ odds of anaemia compared to those coming from the communities with a high percentage of education. The ICC in model 3 showed that differences between communities accounted for about $11.1 \%$ of the variation in anaemia among WRA. In addition, the PCV indicated that $33.9 \%$ of the variation in WRA anaemia between communities was explained by communitylevel characteristics.

In model 4, women who had undergone female sterilisation were at higher (aOR: 3.61, 95\% CI: 1.10 to 11.84) odds of anaemia compared to those who did not use contraceptive methods. Women with no formal education were found to have two times higher $(\mathrm{aOR}=1.99,95 \% \mathrm{CI}: 1.17$ to 3.39$)$ odds of anaemia compared to women who had higher education. Women from middle socioeconomic family had higher $(\mathrm{aOR}=1.65,95 \% \mathrm{CI}: 1.02$ to 2.68$)$ odds of anaemia compared to poorest counterparts. Women who came from province 2 ( $\mathrm{aOR}=2.97,95 \%$ CI: 1.52 to 5.82 ) had higher odds of anaemia compared to Bagmati province. The older women had $49 \%$ lower $(\mathrm{aOR}=0.51$, $95 \%$ CI: 0.26 to 0.97 ) odds of anaemia compared to younger women, and women who used hormonal contraceptive methods had $37 \%$ lower $(\mathrm{aOR}=0.63$, 95\% CI: 0.43 to 0.90 ) odds of anaemia compared to who did not use contraceptive methods. After the inclusion of both the individual and community-level variables in model 4 , the ICC indicated that $9.5 \%$ of the variability in anaemia among WRA was attributable to the difference between communities. Furthermore, the PCV indicated that $44.6 \%$ of the variation in anaemia among WRA between communities was explained by both individual and community-level characteristics (table 2). 
Table 1 Sociodemographic characteristics and prevalence of anaemia among women of reproductive age by determining factors $(n=6414)$

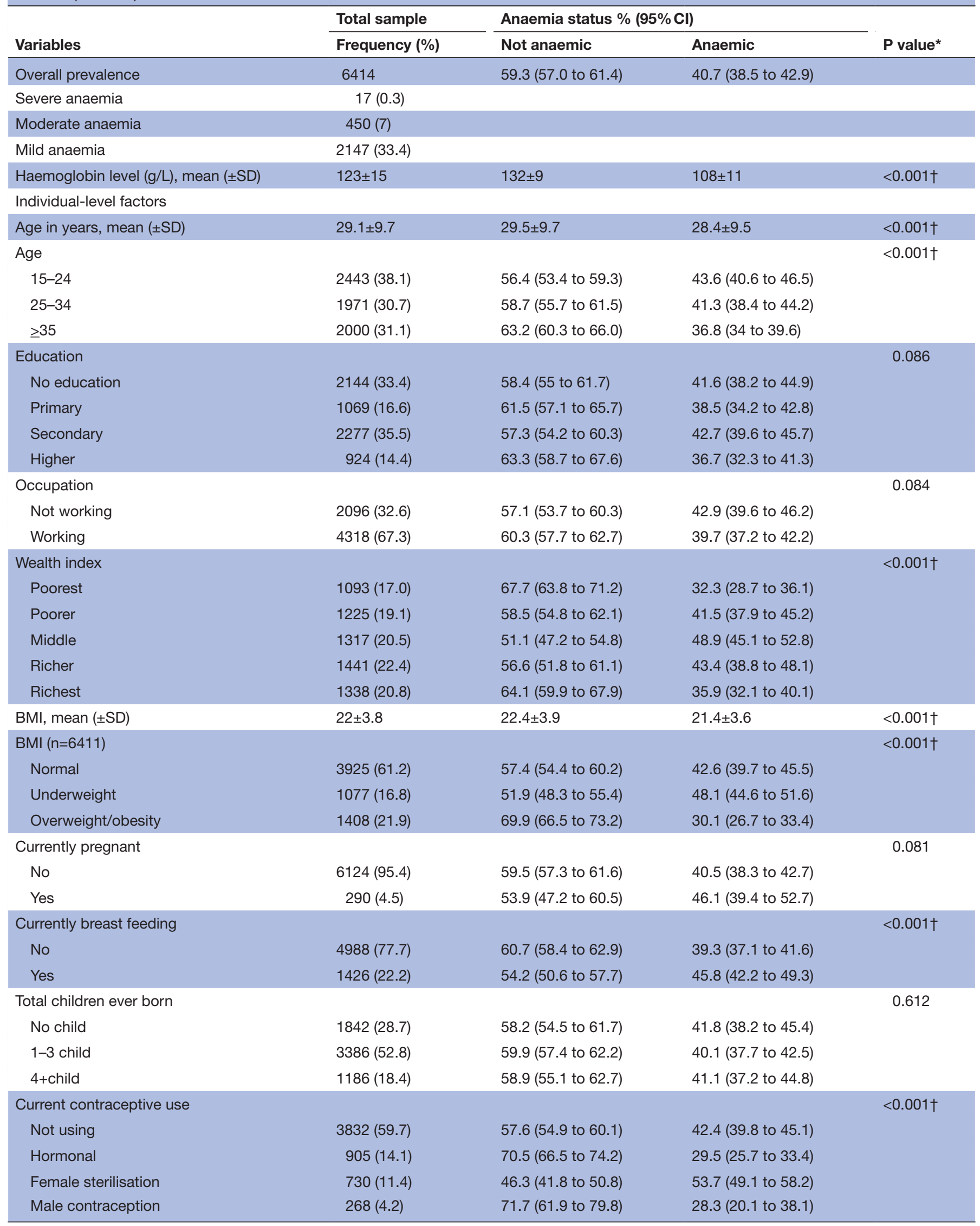


Table 1 Continued

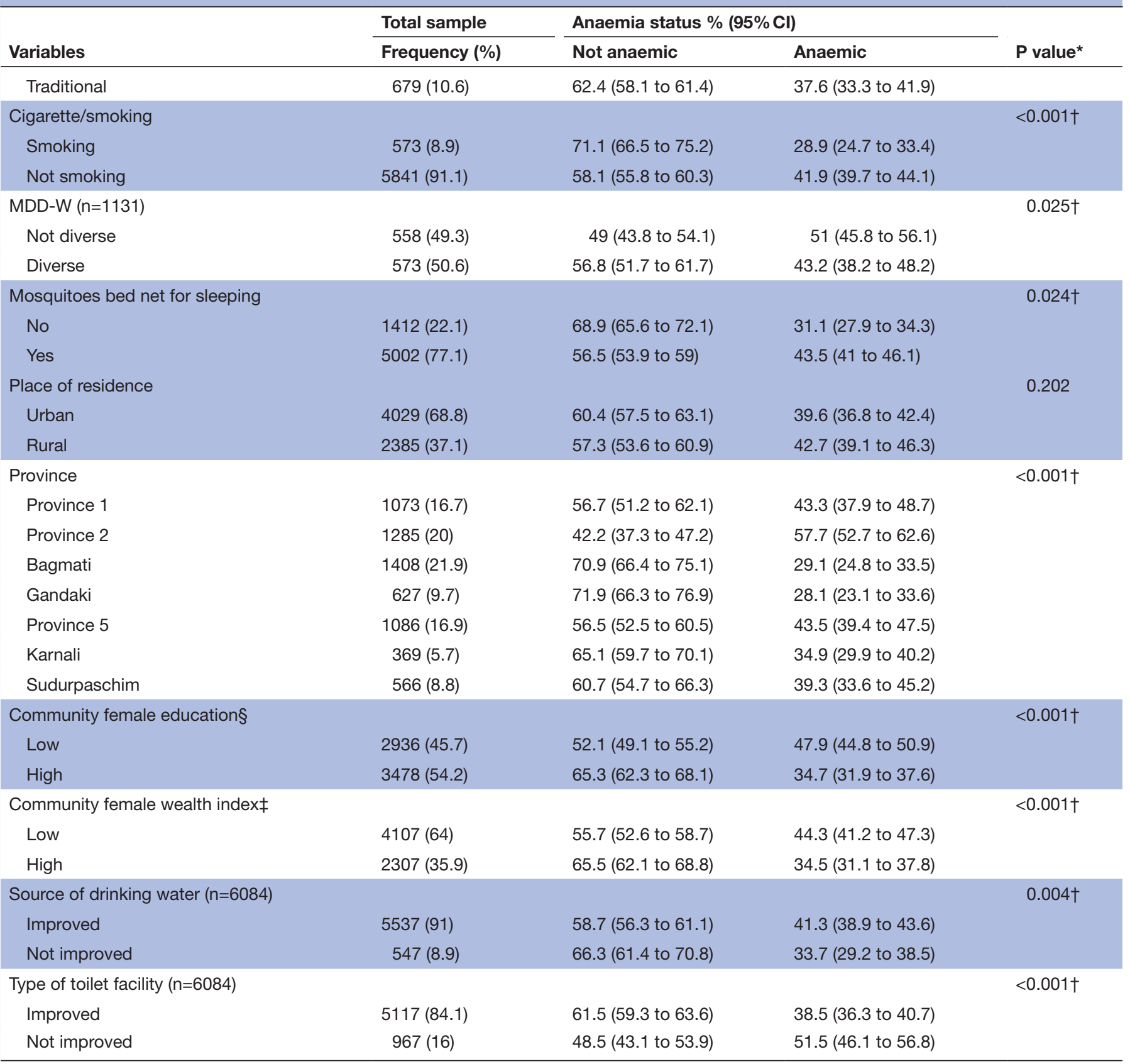

Frequency and percentage (\%) are weighted.

${ }^{*}$ Denotes Pearson $\mathrm{X}^{2}$ test for categorical variables and independent t-test for continuous variables.

†Denotes statistically significant at $p<0.05$.

‡Mean per cent of households wealth quintiles categorised richer and richest and above

$\S M e a n$ per cent of women with primary education level and above.

$\mathrm{BMI}$, body mass index; MDD-W, minimum dietary diversity for women.

\section{Spatial data analysis}

Figure 3A shows the prevalence of anaemia among WRA across provinces in Nepal. A severe anaemia prevalence $(\geq 40 \%)$ among WRA was seen in province 2 , followed by province 1 and 5 . The prevalence of moderate anaemia $(20.0 \%-39.9 \%)$ was observed in Bagmati, Gandaki, Karnali and Sudurpaschim province. Mild anaemia (prevalence $<19.9 \%$ ) was not found in any provinces. Figure $3 \mathrm{~B}$ shows the prevalence of anaemia among WRA across 75 districts in Nepal. The prevalence rate of severe anaemia was observed in 29 out of 75 districts, and mild anaemia was found in only eight districts (figure 3).

The SPR by provinces (standardised to the national mean prevalence of $41 \%$ ) are shown in figure $4 \mathrm{~A}$, and ranged from 0.68 to 1.4 . The higher prevalence ratio of anaemia was found in province 2 , whereas a lower prevalence ratio was observed in Bagmati, Gandaki and Karnali 
Open access

Table 2 Multilevel mixed-effects logistic regression analysis for individual and community-level factors affecting anaemia among women of reproductive age $(n=6414)$

\begin{tabular}{|c|c|c|c|c|}
\hline Variables & $\begin{array}{l}\text { Model } 1 \text { empty } \\
\text { model }\end{array}$ & $\begin{array}{l}\text { Model } 2 \text { Individual- } \\
\text { level factors } \\
\text { aOR }(95 \% \mathrm{Cl})\end{array}$ & $\begin{array}{l}\begin{array}{l}\text { Model } 3 \text { community-level } \\
\text { factors }\end{array} \\
\text { aOR }(95 \% \mathrm{Cl})\end{array}$ & $\begin{array}{l}\text { Model } 4 \text { individual and } \\
\text { community-level factors } \\
\text { aOR }(95 \% \mathrm{Cl})\end{array}$ \\
\hline \multicolumn{5}{|l|}{ Fixed-effects model } \\
\hline \multicolumn{5}{|l|}{ Individual-level factors } \\
\hline \multicolumn{5}{|l|}{ Age } \\
\hline $15-24$ & & 0.80 (0.57 to 1.08$)$ & & 0.75 (0.54 to 1.04$)$ \\
\hline$\geq 35$ & & $0.48(0.24 \text { to } 0.83)^{\star}$ & & $0.51(0.26 \text { to } 0.97)^{\star}$ \\
\hline \multicolumn{5}{|l|}{ Education } \\
\hline No education & & $2.22(1.35 \text { to } 3.82)^{\star \star}$ & & $1.99(1.17 \text { to } 3.39)^{*}$ \\
\hline Primary & & 1.52 (0.99 to 2.63$)$ & & 1.33 (0.79 to 2.23$)$ \\
\hline Working & & 0.98 (0.73 to 1.32$)$ & & \\
\hline \multicolumn{5}{|l|}{ Wealth index } \\
\hline Poorest & & Ref & & Ref \\
\hline Poorer & & $1.20(0.79$ to 1.86$)$ & & $1.46(0.95$ to 2.25$)$ \\
\hline Middle & & $1.38(0.86 \text { to } 2.20)^{\star *}$ & & $1.65(1.02 \text { to } 2.68)^{*}$ \\
\hline Richer & & 1.13 (0.68 to 1.82$)$ & & 1.39 (0.84 to 2.32$)$ \\
\hline Richest & & 1.28 (0.69 to 2.30$)$ & & 1.33 (0.70 to 2.52$)$ \\
\hline \multicolumn{5}{|l|}{ BMI $(n=6411)$} \\
\hline Normal & & Ref & & Ref \\
\hline \multicolumn{5}{|l|}{ Currently breast feeding } \\
\hline No & & Ref & & Ref \\
\hline Yes & & 1.34 (0.63 to 2.82$)$ & & 1.60 (0.71 to 3.59$)$ \\
\hline \multicolumn{5}{|l|}{ Total children ever born } \\
\hline No child & & Ref & & Ref \\
\hline 1-3 child & & - & & - \\
\hline $4+$ child & & 1.15 (0.75 to 1.87$)$ & & 1.02 (0.63 to 1.63$)$ \\
\hline \multicolumn{5}{|c|}{ Current contraceptive use } \\
\hline Not using & & Ref & & Ref \\
\hline Hormonal & & $0.65(0.46 \text { to } 0.92)^{*}$ & & $0.63(0.43 \text { to } 0.90)^{*}$ \\
\hline Female sterilisation & & $3.55(1.21 \text { to } 10.44)^{*}$ & & $3.61(1.10 \text { to } 11.84)^{*}$ \\
\hline Male contraception & & $0.92(0.17$ to 4.79$)$ & & $0.74(0.14$ to 3.77$)$ \\
\hline Traditional & & $1.10(0.74$ to 1.63$)$ & & 1.12 (0.74 to 1.69$)$ \\
\hline \multicolumn{5}{|l|}{ Cigarette/smoking } \\
\hline Smoking & & 0.89 (0.48 to 1.66$)$ & & 1.21 (0.63 to 2.33 ) \\
\hline Not smoking & & Ref & & Ref \\
\hline \multicolumn{5}{|l|}{ MDD-W $(n=1131)$} \\
\hline Not diverse & & 1.20 (0.91 to 1.59$)$ & & 1.03 (0.76 to 1.40$)$ \\
\hline
\end{tabular}


Table 2 Continued

\begin{tabular}{|c|c|c|c|c|}
\hline Variables & $\begin{array}{l}\text { Model } 1 \text { empty } \\
\text { model }\end{array}$ & $\begin{array}{l}\text { Model } 2 \text { Individual- } \\
\text { level factors }\end{array}$ & $\begin{array}{l}\begin{array}{l}\text { Model } 3 \text { community-level } \\
\text { factors }\end{array} \\
\text { aOR }(95 \% \mathrm{Cl})\end{array}$ & $\begin{array}{l}\text { Model } 4 \text { individual and } \\
\text { community-level factors }\end{array}$ \\
\hline Diverse & & Ref & & Ref \\
\hline \multicolumn{5}{|l|}{ Mosquitoes bed net for sleeping } \\
\hline No & & 0.57 (0.38 to 0.86$)$ & & \\
\hline Yes & & Ref & & \\
\hline \multicolumn{5}{|l|}{ Place of residence } \\
\hline Urban & & & Ref & Ref \\
\hline Rural & & & $1.01(0.83$ to 1.21$)$ & $0.89(0.64$ to 1.24$)$ \\
\hline \multicolumn{5}{|l|}{ Province } \\
\hline Province 1 & & & $1.70(1.23 \text { to } 2.34)^{* *}$ & $2.07(1.57 \text { to } 5.64)^{* *}$ \\
\hline Province 5 & & & $1.60(1.16 \text { to } 2.21)^{* * *}$ & $2.42(1.31 \text { to } 4.50)^{\text {*** }}$ \\
\hline Karnali & & & 1.19 (0.85 to 1.66$)$ & $1.66(0.88$ to 3.14$)$ \\
\hline Sudurpaschim & & & 1.54 (1.11 to 2.15$)^{*}$ & $1.62(0.84$ to 3.10$)$ \\
\hline \multicolumn{5}{|l|}{ Community female education $† \S$} \\
\hline Low & & & $1.39(1.15 \text { to } 1.68)^{\text {t*t* }}$ & - \\
\hline High & & & Ref & - \\
\hline \multicolumn{5}{|l|}{ Community wealth index $\neq \S$} \\
\hline Low & & & $1.48(1.21 \text { to } 1.80)^{\text {tot* }}$ & - \\
\hline High & & & Ref & - \\
\hline Not improved & & & $1.03(0.84$ to 1.24$)$ & $0.96(0.63$ to 1.45$)$ \\
\hline \multicolumn{5}{|l|}{ Random-effects model } \\
\hline Community-level variance $(\tau)(\mathrm{SE})$ & $0.627(0.073)^{-1 * t}$ & $0.443(0.192)^{t+* *}$ & $0.414(0.056)^{t+t+t}$ & $0.347(0.194)^{* *}$ \\
\hline ICC (\%) & 16 & 11.8 & 11.1 & 9.5 \\
\hline PCV (\%) & Ref & 29.3 & 33.9 & 44.6 \\
\hline \multicolumn{5}{|l|}{ Model fit statistics } \\
\hline $\mathrm{AIC}$ & 8322.6 & 1554.7 & 7838.4 & 1400.6 \\
\hline $\mathrm{BIC}$ & 8336.1 & 1675.8 & 7925.8 & 1559.1 \\
\hline
\end{tabular}

Model 1 (empty model): without adjusted predictors variables; model 2: adjusted for individual-level factors; model 3: adjusted for community-level factors; model 4: adjusted for both individual-level and community-level factors.

${ }^{*} p<0.05,{ }^{* *} p<0.01,{ }^{* * *} p<0.001$.

tMean per cent of women with primary education level and above.

$\ddagger$ Mean per cent of households wealth quintiles categorised richer and richest and above.

$\S$ Community female education and community wealth index is omitted in Model four due to collinearity.

AIC, Akaike information criterion; aOR, adjusted OR; BIC, Bayesian information criterion; BMI, body mass index; ICC, intraclass correlation; MDD-W, minimum dietary diversity for women; PCV, percentage change in variation; Ref, reference category.

province. Figure 4B shows the SPR across the 75 districts, and ranged from 0.76 to 1.59 . The higher SPR of anaemia was observed in 17 out of 75 districts across the country (figure 4).
The spatial pattern and distribution of anaemia among WRA at the cluster level are displayed in figure 5. The spatial analysis at the cluster level showed that statistically significant high hotspots of anaemia were observed in the 

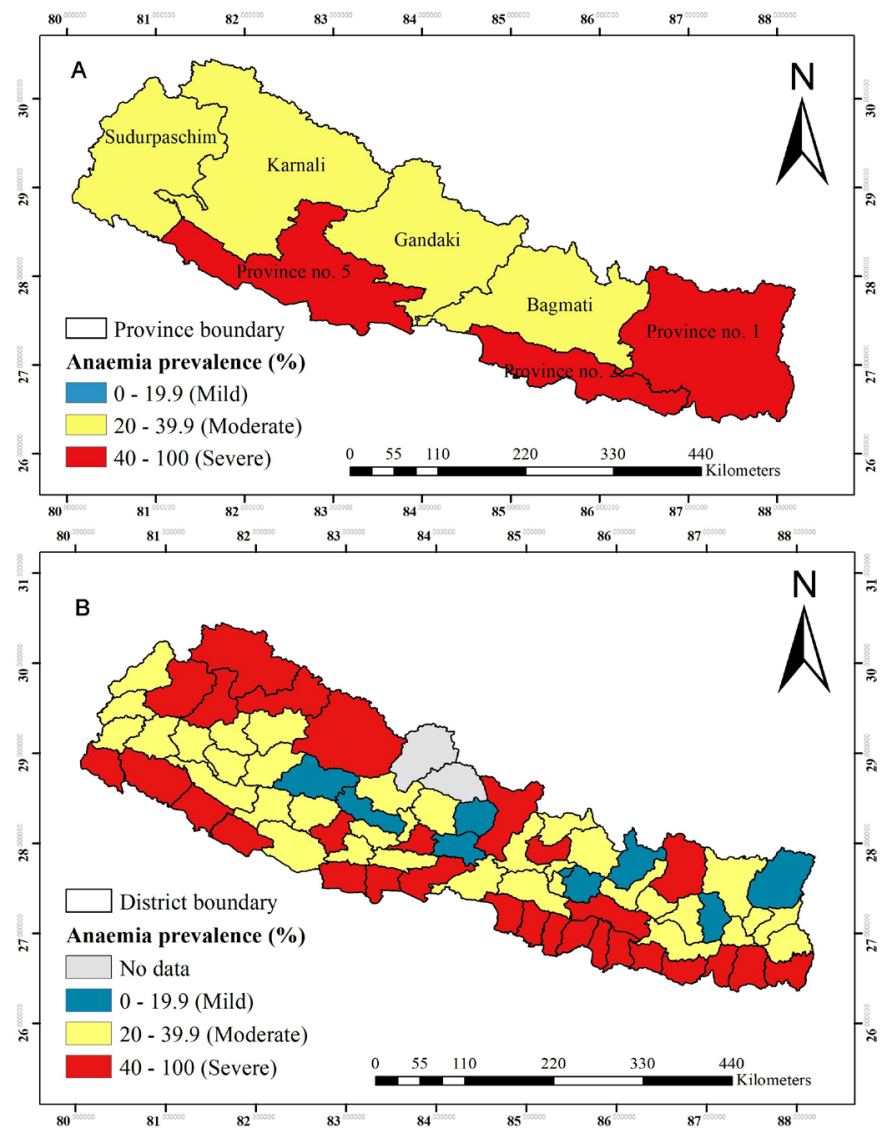

Figure 3 (A) Prevalence of anaemia among women of reproductive age across provinces. (B) Prevalence of anaemia among women of reproductive age across districts.

southern Terai of the country bordering India: province 2 (eight districts), province 1 (four districts), southern plain of the Bagmati province (one district) southwestern region of province 5 (two districts) and southern plain of Sudurpaschim province (one district). While, cold spots of anaemia were observed in most of the Hilly regions of the country (figure 5).

\section{DISCUSSION}

In this study, more than $40 \%$ of WRA were anaemic which implies that anaemia is still an important public health problem in Nepal. ${ }^{40}$ Geographical patterns showed that anaemia is an important public health problem in three of the seven provinces and 29 out of the 75 districts in Nepal. The higher prevalence of anaemia was observed in the southern Terai bordering India particularly in province 2, and the upper Himalayan region of the country. The spatial analysis at the cluster level showed that high hotspots of anaemia were observed in Terai region especially in provinces 1, 2, 5 and Sudurpaschim. These findings are consistent with a previous study, ${ }^{57}$ which was based on the analysis of Nepal National Micronutrient Status Survey 2016 and found WRA living in the Terai ecological zone had higher odds of anaemia relative to women living in the Mountain and Hill regions. A possible reason could be that in the Terai region, there is a shortage of safe and

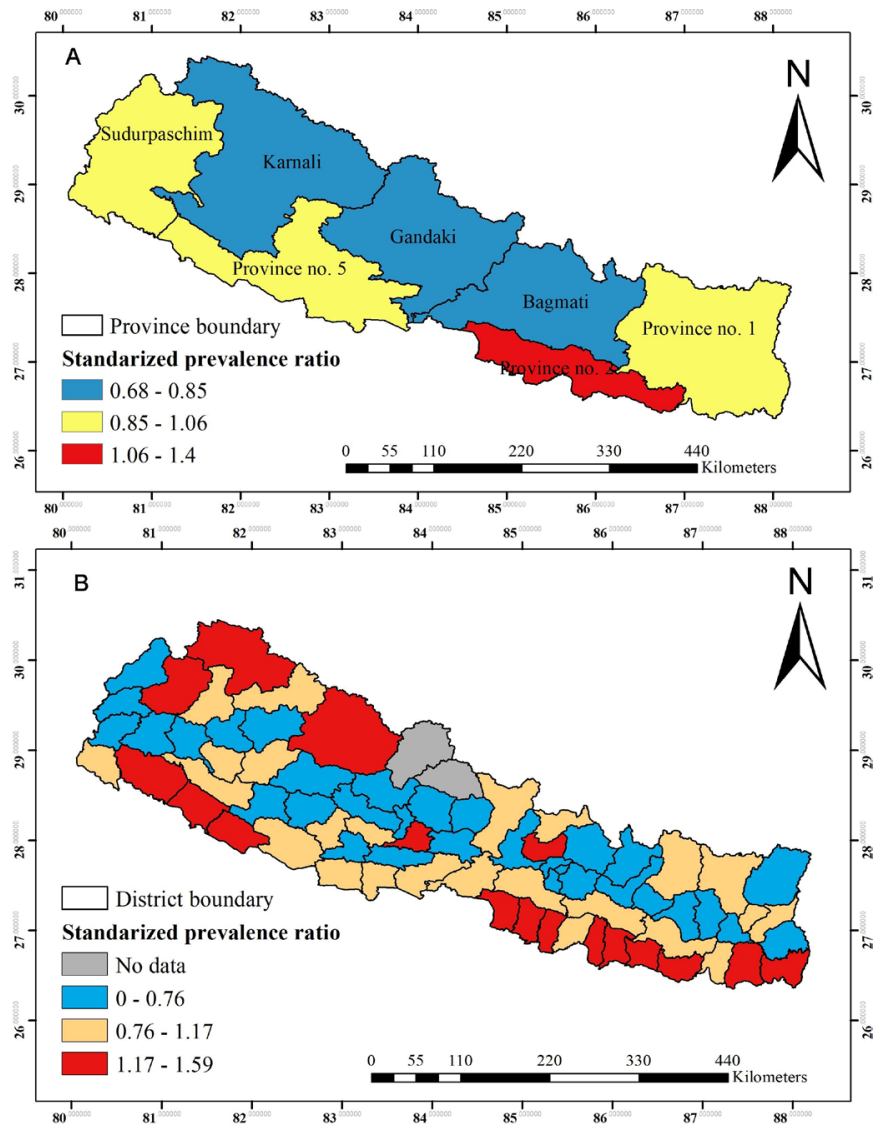

Figure 4 (A) Standardised prevalence ratio of anaemia among women of reproductive age across provinces. (B) Standardised prevalence ratio of anaemia among women of reproductive age across districts (standardised to the national mean prevalence of $41 \%$ ).

adequate drinking water supply and the risks of malaria and hookworm infestations are high. ${ }^{30}$

In the southern Terai of Nepal, despite ecological richness, people have long suffered from a deficiency of micronutrients such as Vitamin A, iron and zinc, ${ }^{26}$ and a high burden of hookworm infestations and malaria which can contribute to development of anaemia. ${ }^{30}$ Diet of women in the Terai lack diversity and, nutrient adequacy which pose an increased risk of anaemia. ${ }^{27}$ Terai region of Nepal is endemic to malaria in contrast to Hill and Mountain region of Nepal, ${ }^{31} 3258$ and thus poses higher risk of anaemia. ${ }^{30}$ The majority $(90 \%)$ of the population from Terai region rely on groundwater especially shallow tube well for domestic purposes including drinking whereas most of the people from Mountain and Hill region rely on municipal taps, spring water source, and stone spouts as drinking water sources. Terai region is the most densely populated region compared to Hill and Mountain regions of Nepal. The population of Terai increased dramatically after the 1970 s because people from the Mountains and Hills migrated to for permanent settlement. ${ }^{33}$ Most of the water wells were installed to meet the growing population demand. However, well water in the Terai consists of high arsenic concentrations $(>10 \mu \mathrm{g} / \mathrm{L})$ 


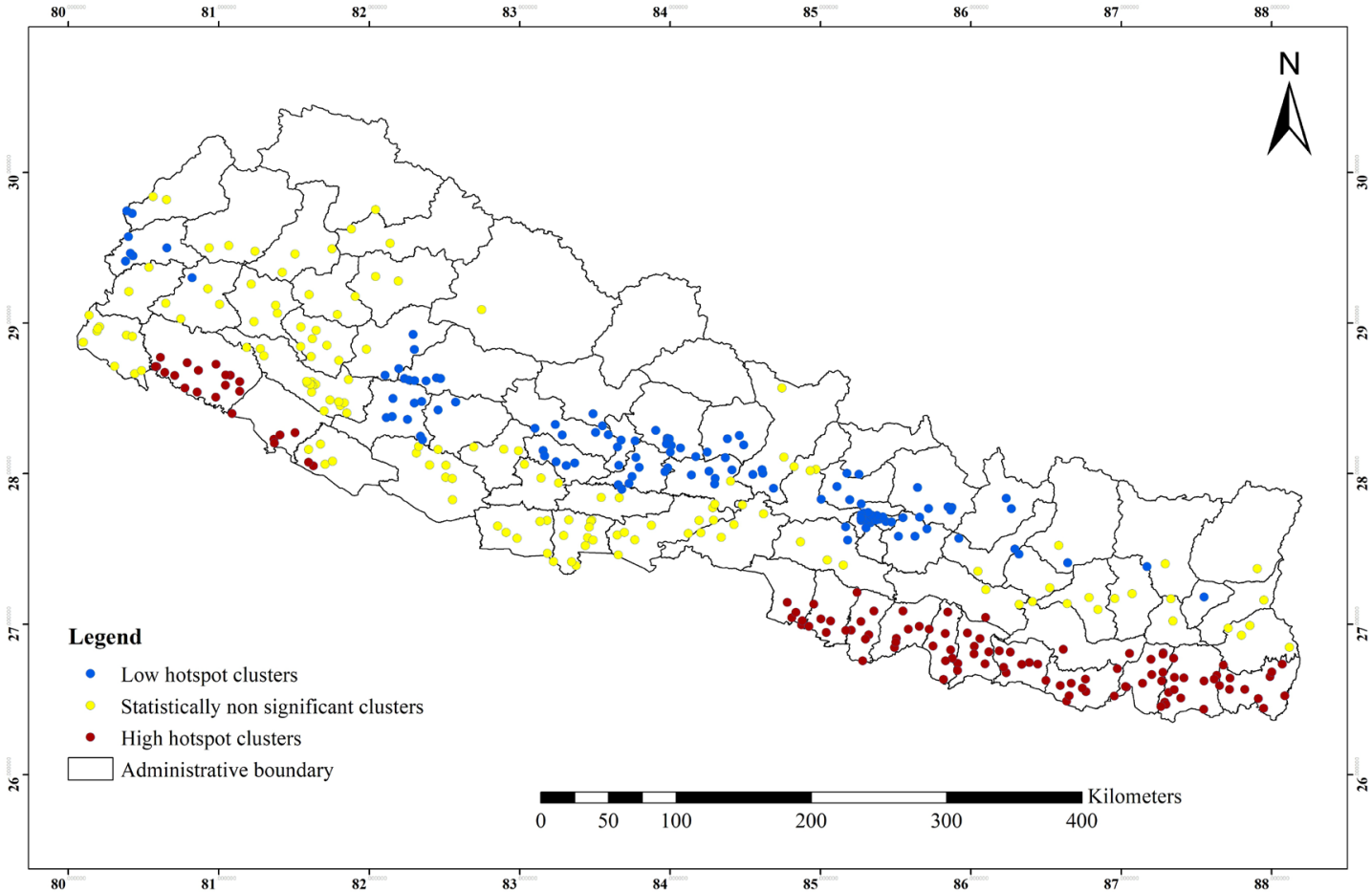

Figure 5 Spatial pattern and distribution of hot and cold spots of anaemia among women of reproductive age at cluster level in Nepal.

beyond the WHO recommendation. ${ }^{33}$ A previous study also explained the high burden of anaemia might be due to chronic exposure to arsenic in drinking water. ${ }^{57}$ Higher arsenic concentration can inhibit haem iron metabolism and increase erythrocyte hemolysis. ${ }^{59}$ Consequently, drinking arsenic-containing water poses an increased risk of anaemia among women. ${ }^{60}$ Arsenic exposure was more likely to cause anaemia among women in Bangladesh. ${ }^{61}$ The spatial analysis at the cluster level found that high hotspots of anaemia were also observed in southwestern region (province 5 and southern plain of Sudurpaschim province), particularly Banke, Bardiya and Kailali district. A previous study highlighted that glucose 6 phosphate dehydrogenase (G6PD) deficiency, sickle cell trait (SCT) and sickle cell anaemia as the most common disorders in Tharu communities living in southwestern province 5 , and sudurpaschim province. ${ }^{62}{ }^{63}$ Study based on the Nepal National Micronutrient Status Survey 2016 also found the G6PD and haemoglobinopathies had strong association with anaemia among WRA. ${ }^{57}$

The geographical variance of high cases of anaemia across the high Mountainous region could be attributed to food insecurity, low dietary diversity, ${ }^{12} 2734$ less calorie diet, ${ }^{27}$ poor health service coverage, ${ }^{25}$ high illiteracy, gender based-inequality and poor health-seeking behaviour. $^{2324}$

\section{Sociodemographic characteristic among women and anaemia}

Women who had no formal education, and those who came from middle socio-economic households, and from younger age group were at increased risk of anaemia. These findings are in line with previous studies from low-income and middle-income countries including Ethiopia, ${ }^{39}$ India, ${ }^{64}$ Tanzania, ${ }^{65}$ Rwanda, ${ }^{66}$ Timor-Leste $^{67}$ and Bangladesh. ${ }^{68}$ Studies from Ethiopia and Tanzania suggest that higher-level education might enable women to gain knowledge and improve attitude which in turn can promote them to adopt healthier lifestyle including good nutrition habits, better health-seeking behaviour and good hygiene practices. ${ }^{39} 65$

Anaemia is a multifaceted problem where nutrition and household economic status are considered to have a synergistic association. ${ }^{66}$ Women belonging to poorer households are more likely to be anaemic compared to those living in middle or richer households in most of the countries. ${ }^{17} 3966$ Contrastingly, this study revealed that socio-economically poorer women were less likely to be anaemic. Similar findings were reported by a previous study which was based on the analysis of the 2016 NDHS dataset. ${ }^{36}$ The possible reason could be first, Nepal is an agrarianbased country and the staple diet may be similar for most of the households. ${ }^{69}$ Second, it might be due to the nationwide open defecation free campaign initiated after 2011, which contributed to the reduction in hookworm infestation leading to decrease in anemia. ${ }^{36}$ Third, there was various ongoing health and nutrition intervention programme targeted at poorer households. For instance, promoting consumption of ironrich dark green leafy vegetables available from their kitchen garden, ${ }^{70}$ consumption of animal source foods, 
and dietary iron consumption. Interventions such as Suaahara I (from 2011 to 2016) and Sunaula Hazar Din (from 2014 to 2017), which provided financial and technical support to poor households for poultry farming, and contributed to increased consumption of meat and eggs among WRA. ${ }^{71} 72$ Future studies are critical to explore the association of household economic status and anaemia among WRA in Nepal.

In this study, the prevalence of anaemia was found to be decreasing with increasing age. These findings are consistent with studies from Nepal, ${ }^{36}$ Ethiopia, ${ }^{39}$ Demographic Republic of Congo ${ }^{73}$ and Benin. ${ }^{60}$ The possible reason could be that the low fertility rates are high among older women. ${ }^{39}$ Also, it might be due to young girls being under-represented in the public health programmes that aim to prevent anaemia in Nepalese context. ${ }^{36}$ However, government of Nepal has started weekly iron folic acid supplementation to adolescent girls aged 10-19 years only after $2016 .{ }^{74}$ In contrast, few studies from Nepal did not show any association of age with anaemia. ${ }^{35}$ The discrepancies might be due to the nature of statistical model used in the analysis.

\section{Effect of contraceptive use on anaemia}

In this study, those using hormonal contraceptive were less likely to be anaemic among WRA which is consistent with previous studies conducted in Nepal, ${ }^{35}{ }^{36}$ Rwanda, ${ }^{66}$ Tanzania $^{65}$ and Ethiopia. ${ }^{75}$ This could be due to multiple reasons. For instance, use of hormonal contraceptive can reduce the blood loss during the menstruation. $^{76} 77$ Almost $100-150 \mathrm{mg}$ of iron is lost during menstrual bleeding. ${ }^{78}$ Subsequently, this may directly or indirectly furnish iron loss among women at high risk for iron-deficiency anaemia. ${ }^{77} \mathrm{~A}$ previous study also suggested that Depo-Provera injections were more likely to increase haemoglobin concentration among WRA in Nepal. ${ }^{79}$ Interestingly, in this study, women who had undergone female sterilisation were at increased risk of anaemia. These findings are in line with the similar study conducted in Nepal. ${ }^{3680}$

\section{Community-level factors and anaemia}

In this study, estimated ICC shows that about $9.5 \%$ of the community level variability was attributable to the difference between communities among WRA. The PCV indicated that $44.6 \%$ of the variation in WRA anaemia between communities was explained by both individual and community-level characteristics. These findings are in line with the study conducted in Ethiopia, where both individual-level and community-level factors accounted for about $43 \%$ of the variability of anaemia among WRA. ${ }^{39}$ Women who came from province 2 had more than two times higher odds of anaemia. Previous studies reported that women from province number 2 were more likely to be coming from lower socioeconomic status and had less diverse diet (an estimated 29\% of MDD). ${ }^{12} 29$ Other evidence from Nepal also suggested that women in province 2 have poor nutritional status. ${ }^{81}$ In addition, compliance rate of recommended dose of iron tablets among the pregnant mothers in province 2 was also low (28\%) compared to other provinces. ${ }^{12}$ This study showed that promoting community female education has a potential role in lowering the likelihood of anaemia which echoes with a study from Malawi. ${ }^{42}$ This could be explained by the fact that higher community education provides a context where women are enabled to gain nutritional knowledge and material resources ${ }^{28}$ that can increase consumption of iron-absorptionenhancers such as vitamin C, phytates (whole grains, legumes) and calcium (dairy products). Increasing community-level education can play an important role in promoting knowledge and attitude which in turn can incite them to adopt healthier lifestyle including good nutrition habits that can ultimately prevent anaemia. ${ }^{396570}$

\section{Strength and limitation}

This study is conducted based on the spatial pattern and multilevel epidemiological analysis of anaemia among WRA in Nepal using cluster sampling of nationally representative data. The combined statistical methods including multilevel and spatial analysis used in this study provides important insights on the role of contextual factors and geographical patterns in the occurrences of anaemia among WRA in Nepal. This study has some limitations. The cross-sectional design of the study does not allow us to establish the causality. This study relied on haemoglobin as the measure of anaemia; further studies should consider other indices that include total ferritin and total iron binding capacity to differentiate the types of anaemia. Since this study is based on the secondary data analysis, we are unable to incorporate potential confounding factors of anaemia such as nutrient intake, worm infestations and other non-modifiable risk factors.

\section{CONCLUSION}

This study highlighted a high prevalence of anaemia among WRA across Nepal. At an individual level, women who had no formal education, those who came from middle socioeconomic class families were more likely to be anaemic, whereas, older women and those who used hormonal contraceptive were less likely to be anaemic. At the community level, low community female education and women living in province 2 were associated with increased odds of anaemia. In the spatial analysis, our study found statistically significant hotspots in the southern Terai region particularly in province 1 (four districts), province 2 (eight districts), Bagmati province (one district) province 5 (two districts) and Sudurpaschim province (one district). Both nutrition specific and nutrition sensitive interventions such as social and behavioural programmes can tailor their strategies based 
on the factors identified in this study to reduce the high burden of anaemia.

\section{Author affiliations}

${ }^{1}$ Department of Nutrition and Dietetics, Armed Police Force Hospital, Kathmandu, Nepal

${ }^{2}$ Department of Public Health, Asian College for Advance Studies, Purbanchal University, Lalitpur, Nepal

${ }^{3}$ Mahidol-Oxford Tropical Medicine Research Unit, Faculty of Tropical Medicine, Mahidol University, Bangkok, Thailand

${ }^{4}$ Agriculture Research, Agricultural Technology Center, Lalitpur, Nepal

${ }^{5}$ Department of Community Medicine, Tribhuvan University Institute of Medicine, Maharajgunj, Kathmandu, Nepal

${ }^{6}$ Nepalese Society of Community Medicine (NESCOM), Kathmandu, Nepal

Twitter Dev Ram Sunuwar @sunuwar_dev and Pranil Man Singh Pradhan @ PranilMSPradhan

Acknowledgements We thank Measure DHS, ICF Macro for granting free access to the data used in this analysis. We are grateful to Professor Dr. Kalpana Tiwari, Director of Research and Planning Purbanchal University, Faculty of Science and Technology, College of Applied Food and Dairy Technology, Kathmandu Nepal for assistance of undertaking this research.

Contributors DRSu: Dev Ram Sunuwar; DRSi: Devendra Raj Singh; BA: Bipin Adhikai; SS: Santosh Shrestha; PMSP: Pranil Man Singh Pradhan. DRSu designed, conceptualized the study, data extraction and analysis, interpreted the results, generate the map, writing an original draft, reviewing, editing and overall supervision of the research. SS generate the map, and writing an original draft. DRSi, BA and PMSP: writing an original draft, reviewing and editing, overall supervision of the research. All authors read and approved the final manuscript.

Funding The authors have not declared a specific grant for this research from any funding agency in the public, commercial or not-for-profit sectors.

Map disclaimer The depiction of boundaries on this map does not imply the expression of any opinion whatsoever on the part of BMJ (or any member of its group) concerning the legal status of any country, territory, jurisdiction or area or of its authorities. This map is provided without any warranty of any kind, either express or implied.

Competing interests None declared.

Patient consent for publication Not required.

Ethics approval The NDHS 2016 was approved by the Nepal Health Research Council (NHRC) and ICF Macro.

Provenance and peer review Not commissioned; externally peer reviewed.

Data availability statement Data are available in a public, open access repository. Dataset used in this study are publicly available from the DHS website (URL: https:// www.dhsprogram.com/data/available-datasets.cfm).

Supplemental material This content has been supplied by the author(s). It has not been vetted by BMJ Publishing Group Limited (BMJ) and may not have been peer-reviewed. Any opinions or recommendations discussed are solely those of the author(s) and are not endorsed by BMJ. BMJ disclaims all liability and responsibility arising from any reliance placed on the content. Where the content includes any translated material, BMJ does not warrant the accuracy and reliability of the translations (including but not limited to local regulations, clinical guidelines, terminology, drug names and drug dosages), and is not responsible for any error and/or omissions arising from translation and adaptation or otherwise.

Open access This is an open access article distributed in accordance with the Creative Commons Attribution Non Commercial (CC BY-NC 4.0) license, which permits others to distribute, remix, adapt, build upon this work non-commercially, and license their derivative works on different terms, provided the original work is properly cited, appropriate credit is given, any changes made indicated, and the use is non-commercial. See: http://creativecommons.org/licenses/by-nc/4.0/.

\section{ORCID iDs}

Dev Ram Sunuwar http://orcid.org/0000-0002-2544-8296

Devendra Raj Singh http://orcid.org/0000-0003-1450-9476

Bipin Adhikari http://orcid.org/0000-0001-8981-3910

Pranil Man Singh Pradhan http://orcid.org/0000-0002-0066-8583

\section{REFERENCES}

1 Benoist BD, McLean E, Egli I, eds. Worldwide prevalence of anaemia 1993-2005, 2008. http://apps.who.int/iris/bitstream/handle/10665/ 43894/9789241596657_eng.pdf?sequence=1

2 Stevens GA, Finucane MM, De-Regil LM, et al. Global, regional, and national trends in haemoglobin concentration and prevalence of total and severe anaemia in children and pregnant and nonpregnant women for 1995-2011: a systematic analysis of populationrepresentative data. Lancet Glob Health 2013;1:16-25.

3 Kassebaum NJ, Jasrasaria R, Naghavi M, et al. A systematic analysis of global anemia burden from 1990 to 2010 . Blood 2014;123:615-24.

4 Sunuwar DR, Singh DR, Chaudhary NK, et al. Prevalence and factors associated with anemia among women of reproductive age in seven South and Southeast Asian countries: evidence from nationally representative surveys. PLoS One 2020;15:e0236449.

5 World Health Organization. Global health observatory data repository/World health statistics, 2016. Available: http://apps.who. int/gho/data/node.main.1lang=en

6 Akseer N, Kamali M, Arifeen SE, et al. Progress in maternal and child health: how has South Asia fared? BMJ 2017;357:j1608.

7 WHO. Global nutrition targets 2025: anaemia policy brief (WHO/ NMH/NHD/14.4), 2014. Available: http://www.who.int//iris/bitstream/ 10665/148556/1/WHO_NMH_NHD_14.4_eng.pdf

8 Harding KL, Aguayo VM, Webb P. Hidden hunger in South Asia: a review of recent trends and persistent challenges. Public Health Nutr 2018;21:785-95.

9 National Planning Committee Government of Nepal. Multi-Sector nutrition plan (2018- 2022), 2017. Available: http://www.nnfsp.gov. np/PublicationFiles/1588f12e-7c45-4506-829d-8fe162da97e5.pdf

10 United Nations. The 17 goals | sustainable development, 2015. Available: https://sdgs.un.org/goals [Accessed 16 Jan 2021].

11 Ministry of Health and Population, New ERA, The DHS Program ICF. Nepal demographic and health survey 2011 2011:163-71.

12 Ministry of Health, New ERA, The DHS Program ICF. Nepal demographic and health survey 2016, 2017. https://www. dhsprogram.com/pubs/pdf/FR336/FR336.pdf

13 World Health Organization. Department of nutrition for health and development. iron deficiency anaemia: assessment, prevention and control: a guide for programme managers. Geneva: World Health Organization, 2001: 1-114.

14 Scholl TO, Hediger ML, Fischer RL, et al. Anemia vs iron deficiency: increased risk of preterm delivery in a prospective study. Am J Clin Nutr 1992;55:985-8.

15 Szerafin L, Jakó J. [Anemia in pregnancy: characteristics in Szabolcs-Szatmár-Bereg County, Hungary]. Orv Hetil 2010;151:1347-52.

16 Rasmussen K. Is there a causal relationship between iron deficiency or iron-deficiency anemia and weight at birth, length of gestation and perinatal mortality? J Nutr 2001;131:590S-603 https://academic.oup. com/jn/article-abstract/131/2/590S/4686836

17 Balarajan Y, Ramakrishnan U, Özaltin E, et al. Anaemia in low-income and middle-income countries. Lancet 2011;378:2123-35.

18 Rabbani G, Saw A, Sayem A. Differentials in the prevalence of anemia among non-pregnant, ever-married women in Bangladesh : multilevel logistic regression analysis of data from the 2011 Bangladesh Demographic and Health Survey. BMC Womens Health 2015:4-11.

19 Baradwan S, Alyousef A, Turkistani A. Associations between iron deficiency anemia and clinical features among pregnant women: a prospective cohort study. J Blood Med 2018;9:163-9.

20 Sanghvi TG, Harvey PWJ, Wainwright E. Maternal iron-folic acid supplementation programs: evidence of impact and implementation. Food Nutr Bull 2010;31:S100-7.

21 Galloway R, Dusch E, Elder L, et al. Women's perceptions of iron deficiency and anemia prevention and control in eight developing countries. Soc Sci Med 2002;55:529-44.

22 McLean E, Cogswell M, Egli I, et al. Worldwide prevalence of anaemia, WHO vitamin and mineral nutrition information system, 1993-2005. Public Health Nutr 2009;12:444-54.

23 Nepal National Planning Commission. Nepal human development report 2014: beyond geography, 2014. Available: https://www.npc. gov.np/images/category/NHDR_Report_20141.pdf

24 Nepal Development Research Institute and UNFPA. Situational assessment for improved gender based violence prevention and response in selected districts of Nepal, Lalitpur, Nepal, 2017.

25 Adhikari B, Mishra SR. Urgent need for reform in Nepal's medical education. Lancet 2016;388:2739-40.

26 Parajuli RP, Umezaki M, Watanabe C. Diet among people in the Terai region of Nepal, an area of micronutrient deficiency. J Biosoc Sci 2012;44:401-15. 
27 Campbell RK, Talegawkar SA, Christian P, et al. Seasonal dietary intakes and socioeconomic status among women in the Terai of Nepal. J Health Popul Nutr 2014;32:198-216.

28 Sunuwar DR, Sangroula RK, Shakya NS, et al. Effect of nutrition education on hemoglobin level in pregnant women: a quasiexperimental study. PLoS One 2019;14:e0213982.

29 Sunuwar DR, Singh DR, Pradhan PMS. Prevalence and factors associated with double and triple burden of malnutrition among mothers and children in Nepal: evidence from 2016 Nepal demographic and health survey. BMC Public Health 2020;20:405.

30 Dreyfuss ML, Stoltzfus RJ, Shrestha JB, et al. Hookworms, malaria and vitamin A deficiency contribute to anemia and iron deficiency among pregnant women in the plains of Nepal. J Nutr 2000;130:2527-36.

31 Rijal KR, Adhikari B, Ghimire P, et al. Epidemiology of Plasmodium vivax Malaria Infection in Nepal. Am J Trop Med Hyg 2018;99:680-7.

32 Rijal KR, Adhikari B, Adhikari N. Micro-stratification of malaria risk in Nepal: implications for malaria control and elimination. Trop Med Health 2019;47:1-12.

33 Pokhrel D, Bhandari BS, Viraraghavan T. Arsenic contamination of groundwater in the Terai region of Nepal: an overview of health concerns and treatment options. Environ Int 2009;35:157-61.

34 Singh DR, Ghimire S, Upadhayay SR, et al. Food insecurity and dietary diversity among lactating mothers in the urban municipality in the mountains of Nepal. PLoS One 2020;15 doi:10.1371/journal. pone. 0227873

35 Gautam S, Min H, Kim H, et al. Determining factors for the prevalence of anemia in women of reproductive age in Nepal: evidence from recent national survey data. PLoS One 2019;14:e0218288.

36 Rai A, Khan MN, Thapa S. Trends and determinants of anaemia in women of Nepal: a multilevel analysis. Matern Child Nutr 2020;16:1-14.

37 Harding KL, Aguayo VM, Namirembe G, et al. Determinants of anemia among women and children in Nepal and Pakistan: an analysis of recent national survey data. Matern Child Nutr 2018;14:1-13.

38 Rose LE. Nepal | history, population, flag, language, map, \& facts | Britannica. Available: https://www.britannica.com/place/Nepal [Accessed 18 Jan 2021]

39 Kibret KT, Chojenta C, D'Arcy E. Spatial distribution and determinant factors of anaemia among women of reproductive age in Ethiopia: a multilevel and spatial analysis. BMJ Open 2019;9:1-14.

40 World Health Organization. Haemoglobin concentrations for the diagnosis of anaemia and assessment of severity. Geneva: World Health Organization, 2011. http://www.who.int/vmnis/indicators/ haemoglobin.pdf

41 FAO F. Minimum dietary diversity for women: a guide for measurement. Rome FAO 2016.

42 Ntenda PAM, Nkoka O, Bass P, et al. Maternal anemia is a potential risk factor for anemia in children aged 6-59 months in Southern Africa: a multilevel analysis. BMC Public Health 2018;18:1-13.

43 Ntenda PAM, Chuang K-Y, Tiruneh FN, et al. Multilevel analysis of the effects of individualand community-level factors on childhood anemia, severe anemia, and hemoglobin concentration in Malawi. $J$ Trop Pediatr 2018;64:267-78.

44 World Health Organization (WHO), United Nations Children's Fund (UNICEF). WHO and UNICEF joint monitoring programme (JMP) for water supply and sanitation: types of drinking-water sources and sanitation. Geneva, Switzerland, 2015. Available: http://www.wssinfo. org/definitions-methods/\%0Awatsan-categories/

45 Merlo J, Chaix B, Ohlsson $\mathrm{H}$, et al. A brief conceptual tutorial of multilevel analysis in social epidemiology: using measures of clustering in multilevel logistic regression to investigate contextual phenomena. J Epidemiol Community Health 2006;60:290-7.

46 Joseph Hair F F, Black WC, Babin BJ. Multivariate data analysis, 7th edn. Available: https://www.pearson.com/us/higher-education/ program/Hair-Multivariate-Data-Analysis-7th-Edition/PGM263675. html [Accessed 3 Apr 2020].

47 Merlo J, Chaix B, Yang M, et al. A brief conceptual tutorial on multilevel analysis in social epidemiology: interpreting neighbourhood differences and the effect of neighbourhood characteristics on individual health. J Epidemiol Community Health 2005;59:1022-8.

48 Guo G, Zhao H. Multilevel modeling for binary data. Annu Rev Sociol 2000;26:441-62. doi:10.1146/annurev.soc.26.1.441

49 Diez Roux AV. A glossary for multilevel analysis. J Epidemiol Community Health 2002;56:588-94.

50 Goverment of Nepal, Survey Department. Ministry of land management, Coperatives and poverty alleviation, 2020. Available: http://dos.gov.np/
51 North American Cartographic Information Society (NACIS) Collaborators. Natural earth. Available: http://www.naturalearthdata. com/ [Accessed 17 Jun 2020]

52 Ohsawa M, Tanno K, Okamura T, et al. Standardized prevalence ratios for atrial fibrillation in adult dialysis patients in Japan. $J$ Epidemiol 2016;26:272-6.

53 Anselin L, Sridharan S, Gholston S. Using exploratory spatial data analysis to leverage social indicator databases: the discovery of interesting patterns. Soc Indic Res 2007;82:287-309.

54 Liyew AM, Kebede SA, Agegnehu CD. Spatiotemporal patterns of anemia among lactating mothers in Ethiopia using data from Ethiopian demographic and health surveys (2005, 2011 and 2016). PLoS One 2020;15:1-17.

55 Ord JK, Getis A. Local spatial autocorrelation statistics: Distributional issues and an application. Geogr Anal 1995;27:286-306.

56 The DHS Program. Demographic and health surveys. Available: https://www.dhsprogram.com/data/available-datasets.cfm [Accessed 20 Jun 2020].

57 Ford ND, Bichha RP, Parajuli KR. Factors associated with anaemia in a nationally representative sample of nonpregnant women of reproductive age in Nepal. Matern Child Nutr 2020:1-11.

58 Gautam N, Kakchapati S, Shrestha S, et al. Patterns and trends of malaria in 25 risk districts of Nepal from 2001 to 2017. Clin Exp Vaccine Res 2019;8:77-85.

59 Mahmud H, Föller M, Lang F. Arsenic-induced suicidal erythrocyte death. Arch Toxicol 2009;83:107-13.

60 Hopenhayn C, Bush HM, Bingcang A, et al. Association between arsenic exposure from drinking water and anemia during pregnancy. J Occup Environ Med 2006;48:635-43.

61 Heck JE, Chen Y, Grann VR, et al. Arsenic exposure and anemia in Bangladesh: a population-based study. J Occup Environ Med 2008;50:80-7.

62 Ghimire P, Singh N, Ortega L, et al. Glucose-6-phosphate dehydrogenase deficiency in people living in malaria endemic districts of Nepal. Malar J 2017;16:214.

63 Gautam N, Gaire B, Manandhar T. Glucose 6 phosphate dehydrogenase deficiency and hemoglobinopathy in South Western region Nepal: a boon or burden. BMC Res Notes 2019;12:1-6.

64 Balarajan YS, Fawzi WW, Subramanian SV. Changing patterns of social inequalities in anaemia among women in India: cross-sectional study using nationally representative data. BMJ Open 2013;3 doi:10.1136/bmjopen-2012-002233

65 Wilunda C, Massawe S, Jackson C. Determinants of moderate-tosevere anaemia among women of reproductive age in Tanzania: analysis of data from the 2010 Tanzania demographic and health survey. Trop Med Int Health 2013;18:1488-97.

66 Hakizimana D, Nisingizwe MP, Logan J. Identifying risk factors of anemia among women of reproductive age in Rwanda - a crosssectional study using secondary data from the Rwanda demographic and health survey 2014 / 2015. BMC Public Health 2019:1-11 https://www.ncbi.nlm.nih.gov/pubmed/31829161

67 Lover AA, Hartman M, Chia KS. Demographic and Spatial Predictors of Anemia in Women of Reproductive Age in Timor-Leste : Implications for Health Program Prioritization. PLoS One 2014;9.

68 Caulfield LE, Haas JD, Belizán JM, et al. Differences in early postnatal morbidity risk by pattern of fetal growth in Argentina. Paediatr Perinat Epidemiol 1991;5:263-75.

69 Adhikari RK. Food utilization practices, beliefs and taboos in Nepalan overview. United States agency for international developmentglobal health technical report, 2010. Available: http://ghpro. dexisonline.com/sites/default/files/resources/legacy/sites/default/ files/1.367 Nepal Nutrition Overview Rpt 8_16_10 508.pdf [Accessed 19 Jan 2020]

70 Osei A, Pandey P, Nielsen J, et al. Combining home garden, poultry, and nutrition education program targeted to families with young children improved anemia among children and anemia and underweight among nonpregnant women in Nepal. Food Nutr Bull 2017;38:49-64.

71 Cunningham K, Singh A, Pandey Rana P, et al. Suaahara in Nepal: an at-scale, multi-sectoral nutrition program influences knowledge and practices while enhancing equity. Matern Child Nutr 2017;13 doi:10.1111/mcn.12415

72 The World Bank. Nepal Sunaula Hazar Din community action for nutrition project Endline report, 2018. Available: http://documents1. worldbank.org/curated/en/176611539110943044/pdf/SHD-EndlineReport.pdf [Accessed 14 Jan 2021]

73 Kandala NI, Pallikadavath S, Amos Channon A, et al. A multileve approach to correlates of anaemia in women in the Democratic Republic of Congo: findings from a nationally representative survey. Eur J Clin Nutr 2020;74:720-31. 
74 Ministry of Health and Population, New ERA, UNICEF, EU, USAID \&, CDC. Nepal national micronutrient status survey report 2016 | UNICEF Nepal, 2018. Available: https://www.unicef.org/nepal/ reports/nepal-national-micronutrient-status-survey-report-2016 [Accessed 14 Jan 2021].

75 Gebremedhin S, Enquselassie F. Correlates of anemia among women of reproductive age in Ethiopia: evidence from Ethiopian DHS 2005. Ethiop J Heal Dev 2011;25:22-30.

76 Miller L, Hughes JP. Continuous combination oral contraceptive pills to eliminate withdrawal bleeding: a randomized trial. Obstet Gynecol 2003;101:653-61.

77 Bellizzi S, Ali MM. Effect of oral contraception on anemia in 12 lowand middle-income countries. Contraception 2018;97:236-42.
78 Haile ZT, Kingori C, Teweldeberhan AK, et al. The relationship between history of hormonal contraceptive use and iron status among women in Tanzania: a population-based study. Sex Reprod Healthc 2017;13:97-102.

79 Chandyo RK, Strand TA, Ulvik RJ, et al. Prevalence of iron deficiency and anemia among healthy women of reproductive age in Bhaktapur Nepal. Eur J Clin Nutr 2007;61:262-9.

80 Sadatmahalleh SJ, Ziaei S, Kazemnejad A, et al. Menstrual pattern following tubal ligation: a historical cohort study. Int J Fertil Steril 2016;9:477-82.

81 Rai A, Gurung S, Thapa S, et al. Correlates and inequality of underweight and overweight among women of reproductive age: evidence from the $2016 \mathrm{Nepal}$ demographic health survey. PLoS One 2019;14:1-16. 